\title{
MORFOLOGÍA Y DESARROLLO DE LAS ASOCIACIONES DE MIGRANTES MEXICANOS EN ESTADOS UNIDOS. UN SUJETO SOCIAL Y POLÍTICO EXTRATERRITORIAL*
}

\author{
MIGUEL MOCTEZUMA LONGORIA*
}

Resumen. El análisis morfológico de las organizaciones de migrantes desde la perspectiva transnacionalista permite identificar la existencia de varios niveles organizativos. Más específicamente, se puede distinguir a los comités de pueblos o clubes sociales, en tanto organizaciones de primer nivel, de las asociaciones como organizaciones de segundo nivel. En este trabajo se analiza la organización de los migrantes pasando de lo simple a lo complejo para luego volver al punto de partida, lo cual permite dilucidar el desdoblamiento y madurez alcanzados por esas estructuras hasta el momento en que dan origen a un nuevo sujeto social extraterritorial.

Palabras clave. Transnacionalismo, comités de pueblos, asociaciones de migrantes, migrante colectivo, sujeto migrante.

ABSTRACT. A morphological analysis of migrant organizations from a transnational perspective allows us to identify the existence of various organizational levels. Specifically, it is possible to disntinguish peoples' committees or social clubs at the first level and migrant associations at a second level. This study analyzes migrant organizations in their simple and complex forms in order to trace out their evolution to the point of giving rise to a new extraterritorial social subject.

KeYwords. Transnationalism, Peoples' Committees, migrant associations, the collective migrant, migrant subject.

\footnotetext{
El autor agradece a Rubén Puentes y la Fundación Rockefeller el respaldo al proyecto de investigación «Principales circuitos migratorios y cultura de la migración internacional de Zacatecas», a partir del cual este trabajo se deriva como uno de sus productos.

" Profesor-investigador del Doctorado en Estudios del Desarrollo de la Universidad Autónoma de Zacatecas. Correo electrónico: jmmoctez@cantera.reduaz.mx.
} 


\section{INTRODUCCIÓN}

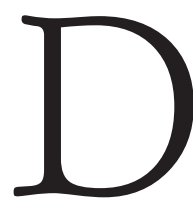
esde finales de la década de los ochenta, del siglo pasado, se habla del transnacionalismo de las comunidades de migrantes mexicanos. Actualmente esta perspectiva, cuya postulación significó un replanteamiento de las interpretaciones dominantes en los estudios de la migración internacional, está centrada, todavía, en el transnacionalismo de individuos y comunidades migrantes. A veces abarca los comités de pueblos o clubes de migrantes que, a pesar de rebasar el ámbito comunitario, suelen autodenominarse comunidades. Pero pocas veces analiza a las asociaciones de migrantes.

Sin apegarse cronológicamente a los hechos, este artículo intenta construir una ruta lógica e histórica acerca de las modalidades que ha conocido la organización social de los migrantes: redes sociales, comunidades filiales, comités de pueblos, organizaciones cívicas y, finalmente, migrante organizado o asociaciones de clubes. A diferencia de las interpretaciones centradas en el trasnacionalismo de individuos y comunidades, se identifican los niveles, rasgos y alcances de cada estructura organizativa, hasta vislumbrar su madurez como nuevo sujeto, social y político, transterritorial. Es decir, se intenta dilucidar el desarrollo y madurez de las prácticas sociales binacionales de los migrantes, su nivel organizativo y los sujetos sociales correspondientes. Se trata de una reflexión circunscrita a la morfología social de la organización transnacional, como parte de una investigación que hemos venido realizando acerca de las remesas colectivas, la inversión social y productiva de los migrantes, la dimensionalidad de las prácticas de las organizaciones de los migrantes, así como la participación social y política transterritorial de los mexicanos (Moctezuma, 2000a, 2000b, 2002, 2003, 2004a y 2004b).

\section{PROBLEMATIZAR}

\section{EL TRANSNACIONALISMO}

Desde sus orígenes, el concepto de transnacionalismo ha sido utilizado con suma ambigüedad y a una velocidad tal que se corre el riesgo de vaciarlo de contenido (Smith y Guarnizo, 1999). La situación se complica debido a su pronta apropiación por la mayor parte de las disciplinas sociales, donde, a pesar de los esfuerzos multidisciplinarios, aún está ausente el tratamiento transdisciplinario. A las dificultades anteriores hay que sumarle el hecho de que al transnacionalismo suele identificársele, preponderantemente, con la práctica de migrantes exitosos, las redes de relaciones sociales y las comunidades filiales que se mueven más allá de las fronteras de los países; además de que, en algunas versiones, el Estado, la Iglesia y otras instituciones políticas están casi ausentes. Contrario a esa tendencia, ya desde los veinte se han encontrado indicios de la existencia de las llamadas 
comunidades hermanas de mexicanos en Estados Unidos, la reproducción de las identidades, la integración y adaptación en los países de destino (sin asimilación total), el funcionamiento de las redes sociales y la influencia de los migrantes en las comunidades de origen. Entonces, si el transnacionalismo tiene, como centralidad, el estudio de esos aspectos, la teoría vive un retraso de más de medio siglo y muchos de los fenómenos «nuevos» no son tales. ${ }^{1}$ Además, de no ser éste el único objetivo del transnacionalismo, habrá que avanzar en su clasificación, acotar sus alcances y delimitar el papel que juegan estos y otros fenómenos relacionados con la temática.

Entre varios transnacionalistas se reconoce que «la investigación puede requerir ser no sólo multilocal sino también translocal [...] [y] se deben dedicar esfuerzos serios a una conceptualización y descripción apropiada de los vínculos translocales y las interconexiones entre ellos y el tráfico social localizado» (Hannerz, 1996). Por su parte, Portes, Guarnizo y Landolt (2003:19), reconocen que:

[...] el transnacionalismo involucra a los individuos, sus redes sociales, sus comunidades y estructuras institucionales más amplias como gobiernos locales y nacionales. La literatura existente sobre el tema tiende a mezclar estos diferentes niveles, refiriéndose a veces a los esfuerzos y logros de migrantes individuales, otras a la transformación de comunidades locales en los países emisores, y otras más a las iniciativas de los gobiernos de estos países que buscan apropiarse de la lealtad y los recursos de sus respectivas emigraciones. Esta mezcla contribuye a una creciente confusión sobre el concepto y su significado.

Como puede apreciarse, los mismos transnacionalistas reflexionan sobre los alcances y aplicaciones del concepto. ${ }^{2}$ El transnacionalismo es un complejo fenómeno moderno asociado a factores tales como:

[...] la globalización del capitalismo con sus efectos desestabilizadores en los países menos industrializados; la revolución tecnológica en los medios de transporte y comunicación; las transformaciones políticas globales como la descolonización y la universalización de los derechos humanos y la expansión de las redes sociales que facilitan la reproducción de la migración transnacional, la organización económica y política (Smith y Guarnizo, 1999: 4).

\footnotetext{
${ }^{1}$ Durand (1994) hace una excelente reseña sobre las investigaciones de Gamio (1930a y 1930b), Taylor (1929, 1930, 1931, 1933) y Santibáñez (1930), quienes, amén de abordar estos temas, incursionan en los enfoques binacionales y combinan las perspectivas etnográfica, antropológica, sociológica, económica y política.

2 Para una clasificación de las distintas perspectivas transnacionalistas, véase, entre otros, a Smith y Guarnizo, 1999; Levitt y Glick Schiller, 2005.
} 
Es decir, estos son temas globales o macrosociales que deben presuponerse como parte del contexto en la discusión.

De todas las dimensiones sociales que el concepto abarca, el estudio de la cultura transnacional es el campo que mayormente ha avanzado, por ello es el más sugerente, pero también el que presenta mayor diversidad y problemas interpretativos. Existen, en esta área, interpretaciones inspiradoras, como aquella que enuncia la construcción de la nacionalidad por los actores sociales y cuestiona las expresiones existencialistas que el Estado ha creado (Bhabha, 1990). Para algunos, lo anterior conduce, erróneamente, a la desaparición del Estado-nación, como bien lo aclaran Basch, Glick Schiller y Szanton Blanc (1994). Para otros, se trata de la construcción, por el Estado del país de origen, de un nuevo sujeto con doble ciudadanía e identidad política múltiple, capaz de desarrollar empoderamiento o subordinación en los Estados de los países de origen y destino (Smith y Guarnizo, 1999). En esta última perspectiva se empieza a hablar de migrantes con distintas formas de ser y pertenecer dentro del fenómeno transnacional (Levitt y Glick Schiller, 2005). Estas formas han sido analizadas como la «transición de la identidad hacia la membresía, donde ésta es práctica y se refiere a las relaciones que se construyen binacionalmente con la comunidad, entidad o nación; en tanto, la identidad es más simbólica»; es decir, en este proceso se transita "del sentimiento perceptivo hacia la acción y el compromiso social más allá de la comunidad o país de origen» (Moctezuma, 2004a y 2004b). Independientemente de que lo anterior sea reconocido en las legislaciones, la membresía es conceptualizada, por algunos autores, como ciudadanía sustantiva o ciudadanía práctica (Brubaker, 1990; Goldrin, 2003).

Los exponentes más lúcidos reconocen la existencia de un campo social transnacional que abarca la dimensión social, económica, política y cultural (Dore, Itzigson, Hernández y Vázquez, 2003; Landolt, Autler y Baires, 2003; Portes, Guarnizo y Landolt, 2003). Empero, en la mayoría de los casos se presta escasa atención a la dimensión organizativa, a lo sumo se le reduce al ámbito de las prácticas entre comunidad de origen y comunidad filial, cuando, en realidad, las relaciones se extienden a varios destinos y abarcan la migración interna e internacional, incluyendo todo un cúmulo de organizaciones sociales (asociaciones).

Mientras gran parte de la literatura se limita a la práctica de individuos y redes sociales, así como a la cultura migrante de las comunidades transnacionales, en este trabajo nos concentramos en los sujetos extraterritoriales y las prácticas de sus organizaciones sociales, a fin de dilucidar la naturaleza de las asociaciones de migrantes, en tanto estructuras de segundo nivel. De este modo se devela la existencia del migrante colectivo como sujeto social transterritorial comprometido, binacionalmente, con las luchas por la identidad, la democracia y el desarrollo comunitario y regional (Moctezuma, 2004a y 2004b), lo cual supone el desarrollo de una conciencia social que conduce, en distintos grados, al empoderamiento y la rendición de cuentas en un sentido más amplio, así como al cuestionamiento de las relaciones tradicionales de poder. 
Desde la dimensión cultural referida a los migrantes y sus comunidades, el transnacionalismo se refiere a la sobrevivencia de distintos cursos de vida; una cierta forma de acoplamiento simultáneo que no necesariamente desaparecerá en las generaciones subsiguientes de los migrantes (Rouse, 1991). La comunidad y la nación son estructuras sociales que dan cuenta del conjunto de relaciones que se producen entre sus miembros, sin sujetarse a las relaciones sociales de un sólo territorio; esto mismo sucede con las identidades, la participación política y otros fenómenos afines. Por lo tanto, trascendiendo el individualismo y la vida comunitaria, se trata de recoger la simultaneidad de las prácticas organizativas, demográficas, sociales, económicas, culturales y políticas, al tiempo que se diferencian y especifican los sujetos sociales partícipes, mediante una mirada transdisciplinaria que abarque más allá de un sólo espacio social. Una perspectiva contraria separa, e incluso confronta, la organización migrante de los intereses de la comunidad de origen, ${ }^{3}$ y no se diga en el caso de los comités de pueblos, junto con sus estructuras paralelas, en las comunidades de origen (Waldinger y Fitzgerald, 2003; Zamudio, 2004), o a nivel regional, como sucede en Zacatecas (García Zamora, 2004a y 2004b) u Oaxaca (Fox y Rivera-Salgado, 2004). En estos casos, la lógica organizacional, del lado mexicano, corresponde a la de una asociación civil con capacidad de emprender distintos proyectos más allá de lo local, a la vez que sirve de soporte y contraparte de las actividades que emprenden las asociaciones de clubes en Estados Unidos.

\section{PRIMERAS ORGANIZACIONES CIVILES}

Varios investigadores han encontrado evidencias de que las primeras organizaciones sociales, de mexicanos en Estados Unidos, datan de la década de los setenta (González, 1995; Honey y Stanley, 1998; Levitt, 2000). En el caso de Zacatecas, los primeros comités de pueblos se organizaron dos décadas antes, bajo la forma de asociación (Moctezuma, 2000b). Las evidencias dan cuenta de que la organización de los migrantes es más antigua y variada de lo que normalmente se cree; por tanto, rastrear sus orígenes ayudará a conocer su desenvolvimiento y a identificar los sujetos que portan, encabezan y dan forma a este proceso. ${ }^{4}$

Las primeras organizaciones de migrantes son, en muchos sentidos, diferentes a las actuales. Sus estructuras organizativas eran informales, sin vida estatutaria, con una membresía inestable y canalizadas más hacia las actividades cívicas

\footnotetext{
${ }^{3}$ La solución práctica que damos, a este asunto, se puede encontrar en la fundamentación de lo que se ha conocido como Ley Migrante de Zacatecas, en donde se reconoce la residencia binacional o simultánea desde la cual se argumenta que los migrantes están presentes desde la distancia o están presentes estando ausentes.

${ }^{4}$ Los antecedentes más remotos de los clubes de migrantes zacatecanos, en el área de Los Ángeles,
} 
y de convivencia social. Sus objetivos estaban explícitos y sus prácticas se diferenciaban poco de las que realizaban los equipos deportivos, los amigos y familiares. Se trataba de actividades en donde la vida comunitaria sobresale de la estructura organizativa, tal como sucede hoy con cualquier comunidad filial de migrantes. ${ }^{5}$

Como hemos expuesto en otro trabajo, los llamados comités de pueblos se derivan de las comunidades filiales, que a su vez proceden de un núcleo de migrantes establecidos (Moctezuma, 2000c, véase figura 1). ${ }^{6}$ Empero, su evolución no es sencilla: todo núcleo de migrantes establecidos se consolida como comunidad filial, pero no toda comunidad filial da origen a la organización migrante (Moctezuma, 2000b). Esta aseveración indica que, por muy sencilla que sea la vida organizativa de los migrantes mexicanos en los sesenta, ya presenta una diferencia cualitativa que da lugar a la vida comunitaria trasnacional. En efecto, aunque en los primeros comités sobrevive la semejanza con las comunidades filiales, en términos estrictos se puede afirmar que los actores ya han trascendido, simbólicamente, el sentido mentado y subjetivo (Weber, 1984) de la acción comunitaria, al tiempo que han arribado a la participación y membresía transnacional (Moctezuma, 2004a y 2004b). En el primer caso, la comunidad resulta de lo que social y culturalmente comparten los miembros de un grupo, ya sea reproduciendo o reestructurando los procesos de socialización primarios y secundarios; en el segundo caso, lo que caracteriza es el involucramiento y compromiso con las prácticas binacionales, los proyectos, las utopías. Esto último es lo que hace posible que se eleven de agentes a sujetos sociales.

La vida y práctica cotidianas de las comunidades filiales, en Estados Unidos, están centradas en las relaciones culturales que los núcleos de migrantes de una misma localidad o región comparten entre sí; sin embargo, su carácter transnacional los lleva a compartir aquellos elementos sociales y culturales de la sociedad de destino. Aun así, sobreviven las percepciones y sentimientos que tienen, como

California, se remontan a 1962, cuando el Club Social Guadalupe Victoria, de Jalpa, Zacatecas, fue fundado por Gregorio Casillas (Revista de la FCZUSC, 1992). Posteriormente, el Club Social Hermandad Latina, promovido por migrantes del municipio de Jerez, Zacatecas, y el Club Social Momax, fundado en 1968 (Revista de la FCZUSC, 1998-99). Para 1971 se agregan los clubes Jalpense, San Vicente, Tlachichila, Tlaltenango y Club Social Zacatecano (Zaldívar, El momento en Los Ángeles, 9 de enero de 1993).

${ }^{5}$ Según Gamio (1930), ya a finales de los años veinte, como resultado de la inmigración mexicana que le antecedió, hubo una gran actividad cívica de los migrantes en ciudades como Los Ángeles, la cual se transformó en los llamados comités de beneficencia para el auxilio de los migrantes repatriados a México (Gamio, 1930; Carreras, 1974).

${ }^{6}$ Los migrantes circulares y estacionales no llegaron a formar comunidades filiales en el extranjero debido a que su permanencia, en Estados Unidos, era relativamente corta, además se trataba de varones solteros o casados sin familia. En cambio, entre los migrantes establecidos, la mujer y la familia son parte del nuevo patrón migratorio y es ella quien mejor reproduce la cultura, así como la vida social propia de las comunidades filiales. Sin este elemento es imposible que se reproduzca la vida comunitaria en su sentido pleno. 
referente simbólico, la territorialidad de las relaciones propias de la comunidad de origen. Los comités de pueblos se nutren de todo esto, sin embargo, por muy sencillos que sean, ya cuentan con una membresía y unos compromisos prácticos que rebasan lo estrictamente simbólico/identitario. Entonces, la distinción conceptual entre comunidades filiales y primeras organizaciones de migrantes se encuentra en la transición que va de la identidad cultural a la membresía; por tanto, «su membresía se refiere a las relaciones prácticas que se construyen binacionalmente con la comunidad, entidad o nación; en cambio, la identidad, aunque incluye elementos prácticos, es más simbólica» (Moctezuma, 2004a y 2004b).

FIGURA 1

COMITÉS DE PUEBLOS EN LOS SESENTAS

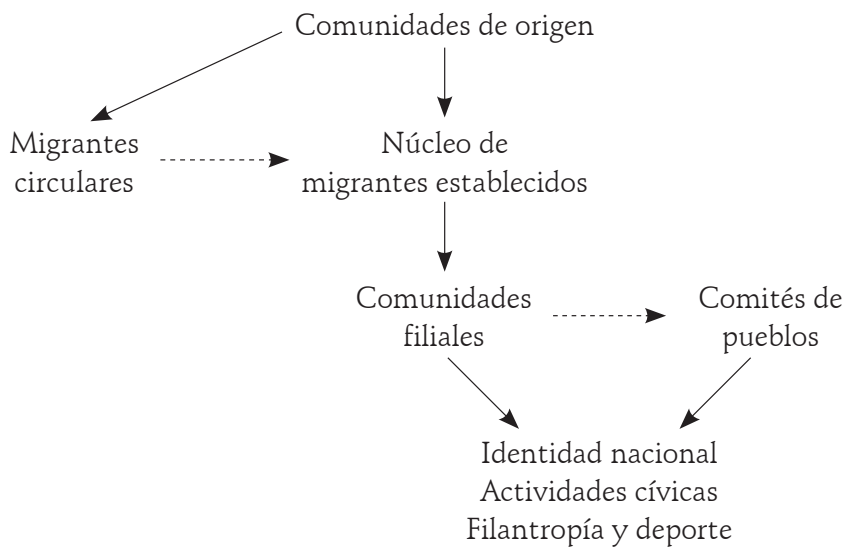

A diferencia de la relación que estas estructuras mantienen con el Estado, sus primeras expresiones estuvieron vinculadas, mayormente, con la Iglesia católica en sus respectivos pueblos, donde sus prácticas, más que religiosas, eran esencialmente sociales y comunitarias, tal es el caso de las actividades de convivencia familiar y deportivas. No es que la Iglesia se interesara en los migrantes, sino que, a través de las prácticas culturales locales, ellos fueron encontrando formas de relacionarse con sus comunidades de origen. Esto es contradictorio, porque en aquella época la Iglesia aún mantenía fuertes resistencias hacia este sector de la población (Espinosa, 1998), por tal razón, la religiosidad de los migrantes se separa de la administración ritual que impone el clero, a la vez que adquiere un sentido y una forma más cultural de religiosidad popular, misma que ahora la Iglesia reconoce y aprovecha.

Uno de los aspectos distintivos, vinculados permanentemente con los comités de pueblos, son las obras sociales que se realizan en sus comunidades de origen. Las obras comunitarias, que en esos años se impulsan, no contaron con desembolsos financieros de los gobiernos, por el contrario, se trataba de aportes 
económicos que los migrantes hicieron en su totalidad. Por supuesto, estas ya son remesas colectivas en donde sus primeras manifestaciones aún permanecen oscuras. Las obras sociales que más emprendieron los primeros migrantes organizados fueron aquellas vinculadas a las parroquias, fiestas del santo patrono, ampliación de escuelas, donación de ambulancias y autobuses, apoyo a las personas desamparadas de la tercera edad y a familias indigentes. Ello se explica por la fuerza de la cultura, el genuino sentimiento filantrópico de los migrantes y la actividad emprendida por sacerdotes y profesores. Dicho sin rodeos: en sus inicios, los migrantes organizados actuaron claramente apegados a sus relaciones de identidad inmediata, en donde sus acciones eran esporádicas, escasas, poco formales e invisibles para la sociedad y el Estado, aspecto que, en muchos casos, aún se mantiene, como se verá más adelante.

Tanto por su nivel organizativo como por la convivencialidad de sus prácticas, tipo de obras y adscripción identitaria, podemos afirmar que estos núcleos organizativos, a lo más, son organizaciones cívicas que aún carecen de una membresía permanente y que desarrollan actividades diversas, las cuales no difieren mucho de lo que hoy en día hacen las comunidades filiales que poseen un sistema de redes fuertes. Por ejemplo, se sabe de migrantes que sólo tienen comunidades, además de redes sociales, y sin embargo ya hacen aportes para los arreglos de la Iglesia del lugar, envíos de dinero para financiar los juegos pirotécnicos de la fiesta del santo patrono, regalos navideños a los niños más humildes de la localidad, compras de ambulancias para el centro de salud o de autobuses para la escuela del lugar, la recaudación de fondos para el traslado de cadáveres, y otras actividades.

Las redes sociales son una característica inherente a las comunidades de los migrantes, pero redes y comunidades son dos conceptos diferenciados entre sí. En sus inicios, las redes pueden ser poco densas, de tipo individual y familiar, sin que lleguen a ser de naturaleza comunitaria (Moctezuma, 2000c). Esto mismo plantea una distinción entre ambos conceptos, ya que, en general, en los lugares de destino, necesariamente florecen las redes sociales, pero esto puede ser un indicio -y sólo eso- de que se está formando la comunidad trasnacional.

Por otra parte, cuando ya se han formado las comunidades hijas, se convierten en la base donde surgen los llamados comités sociales, pero no todas ellas evolucionan por esa senda, lo que a su vez genera otro tipo de redes (más densas y extensas). Se trata, por tanto, de una dialéctica que el devenir histórico no permite dilucidar si antes no se hace un esfuerzo por comprender su naturaleza y su lógica, sin caer en mecanicismos.

\section{COMITÉS SOCIALES COMO ORGANIZACIONES DE}

PRIMER NIVEL A FINALES DE LOS OCHENTAS

En la experiencia de diversas entidades de México, las organizaciones de migrantes se derivan de las comunidades filiales, pero representan una forma superior de 
estructuración organizativa. A su vez, los comités de pueblos son sólo una expresión singular de lo que más tarde serán las asociaciones de clubes de migrantes; se trata, por tanto, de organizaciones comunitarias de primer y segundo nivel, respectivamente. Distinguir estos niveles - y crear metodologías de seguimiento apropiadas- es una tarea indispensable en el proceso de aprehensión, aspecto central que se dilucida en este trabajo (véase figura 2).

En términos de representatividad existe también una diferencia cuantitativa. En el universo de migrantes, las redes sociales y las comunidades filiales son estructuras muy amplias, en cambio, los comités de pueblos son núcleos organizativos con un nivel de representación mucho menor. Aún así, su capacidad de influencia es inversa: a mayor nivel de organización menor universo representado, pero mayor legitimidad y capacidad de negociación con el Estado. Esto mismo es válido para analizar las prácticas que rebasan lo local y terminan convirtiéndose en prácticas plenamente binacionales, propias del trastrocamiento de comunidades y clubes en sujetos. Más adelante se revisará, con detalle, este asunto.

FIGURA 2

COMITÉS DE MIGRANTES, ORGANIZACIONES DE PRIMER NIVEL

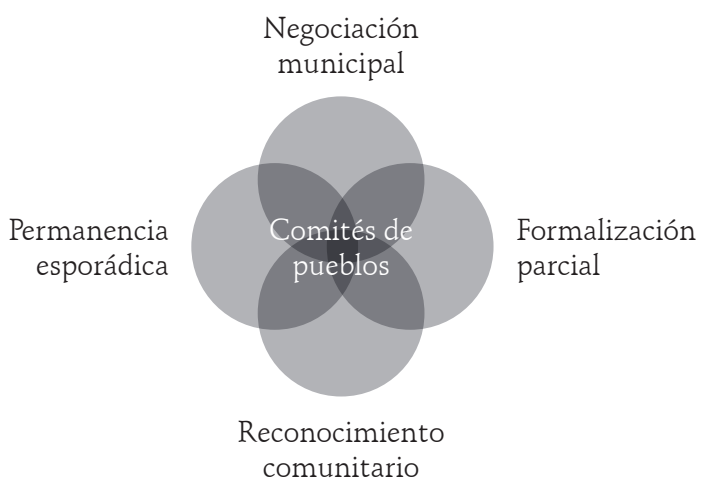

Según se ilustra en la figura dos, no todos los comités de pueblos constituyen estructuras permanentes con alto grado de formalización. Mientras que unos mantienen una expresión organizacional limitada a uno o dos clubes, existen estructuras más complejas, en donde el migrante y sus prácticas sólo pueden ser identificados como parte de la colectividad. Igual que en el caso de las primeras organizaciones, la expresión más simple está muy próxima a la vida social de las comunidades filiales, en tanto que la expresión más compleja llega al grado de perfilar la primera manifestación o la potencialidad de la existencia de un sujeto social capaz de abrir la negociación, inicialmente, con las autoridades de la comunidad y el municipio. Por supuesto, sus posibilidades están también condi- 
cionadas al contexto. Por ejemplo, la primera asociación de clubes de migrantes zacatecanos, a pesar de sus esfuerzos e insistencia, no logró establecer relaciones institucionales con los respectivos gobiernos de Zacatecas (Gregorio Casillas, Entrevista, citado en Lanly y Hamann, 2004).

En la actualidad, no obstante sus limitaciones, los comités de pueblos constituyen estructuras sociales con un mínimo de formalidad, sin que ésta llegue a expresarse en un reglamento estatutario de atribuciones y responsabilidades entre sus miembros. La presencia esporádica muestra, aún, su vulnerabilidad y la falta de objetivos estratégicos. No obstante, como producto de su esfuerzo y tenacidad, actualmente existen agrupaciones de esta naturaleza que llegan a alcanzar un reconocimiento y grado de legitimidad, el cual les permite abrir la puerta a las negociaciones con las autoridades de sus municipios y, en casos excepcionales, con el Estado, como ha sucedido con el Club Comunitario Jamay del estado de Jalisco (Lanly y Hamann, 2004). En este nivel, las remesas colectivas ya son significativas por su monto e impacto, y el Estado resulta muy sensible a ello.

El rasgo característico de estos comités sociales de migrantes es que su práctica es todavía muy local. Toda su actividad y percepción está centrada en las necesidades así como en la identidad que se alimenta del matriotismo cultural de las comunidades de origen, a partir de lo cual se recoge el sentido que González (1986) da a este concepto, es decir, al conjunto de relaciones que establecen los miembros de una misma comunidad cuando se conocen y asumen, permanentemente, compromisos sociales o tienen encuentros en los espacios físicos de su entorno inmediato. ${ }^{7}$ Para el caso de los migrantes mexicanos que han logrado construir organizaciones en el extranjero, el concepto de comunidad matria se refiere a las relaciones que produce la migración en poblaciones pequeñas o de tamaño medio, en donde es factible que sus migrantes desarrollen y fortalezcan sus relaciones basadas en la cultura, junto con los procesos de socialización primarios y secundarios. Se trata de una práctica de afirmación social y simbólica territorializada más allá del espacio social inmediato.

En la mayoría de los casos - y en sentido riguroso- este nivel de organización aún está lejos de ser parte de un sujeto social, ya que no cuenta con experiencia ni con una cosmovisión que rebase los confines comunitarios; simplemente se trata, por tanto, de actores sociales.

${ }^{7}$ Como lo expresa González (1986: 52-53): «[...] El radio de cada una de estas minisociedades se puede abarcar de una sola mirada y recorrer a pie de punta a punta en un sólo día [...] La gente de cada uno de los dos mil municipios mexicanos de dimensiones rústicas suele estar emparentada y conocerse entre sí. Se llaman unos a los otros por su nombre de pila, su apellido y su apodo. Los académicos dicen que en las pequeñas agrupaciones humanas se da el conocimiento interpersonal directo. Hay comunidades como la mía, donde todos los vecinos somos parientes, donde va uno por la calle diciéndoles a los que encuentra: «Que tal primo`, ‘buenos días, tío`, ‘quiubo, compadre». 


\section{ASOCIACIONES DE MIGRANTES}

Así como los comités de pueblos representan una forma superior de organización, en referencia a las comunidades migrantes, las asociaciones representan un grado de mayor madurez respecto de los comités.

Algunos autores han llamado la atención sobre la metamorfosis organizativa que han sufrido los clubes actuales respecto de los clubes mexicanos anteriores. Lo primero que encontraron es que la denominación de sus asociaciones se transforma en una organización por entidad, como la Federación de Clubes Jaliscienses, la Fraternidad Sinaloense, la Asociación de Nayaritas y la Organización Regional de Oaxaca (Goldring, 1997). Sin embargo, la transformación es mucho más específica y compleja: cada asociación está referida no sólo a la entidad mexicana de donde los migrantes proceden, sino también al radio de acción en Estados Unidos, además de incluir varios clubes o comités que han adoptado la denominación de sus comunidades de origen.

Lo distintivo de las asociaciones, como lo expresa un estudioso de las organizaciones de migrantes colombianos existentes en la ciudad de Nueva York, es que mantienen relaciones y prácticas permanentes que llegan a institucionalizarse, por una parte, entre los migrantes y sus organizaciones sociales y, por otra, entre las instituciones políticas de un país y su Estado (Itzigsohn, 2000). Es decir, se trata de estructuras permanentes con un alto grado de formalización, reconocimiento y legitimidad social, basadas en la colectividad y la práctica binacional de sus miembros. En ese sentido, esta práctica va más allá de los individuos, las relaciones propias de las redes sociales, la vida comunitaria y los comités de pueblos, cuya organización configura lo que en otros lados hemos denominado migrante colectivo $u$ organizado, en tanto sujeto social transterritorial (véase figura tres).

FIGURA 3

ASOCIACIONES DE MIGRANTES, ORGANIZACIONES DE SEGUNDO NIVEL

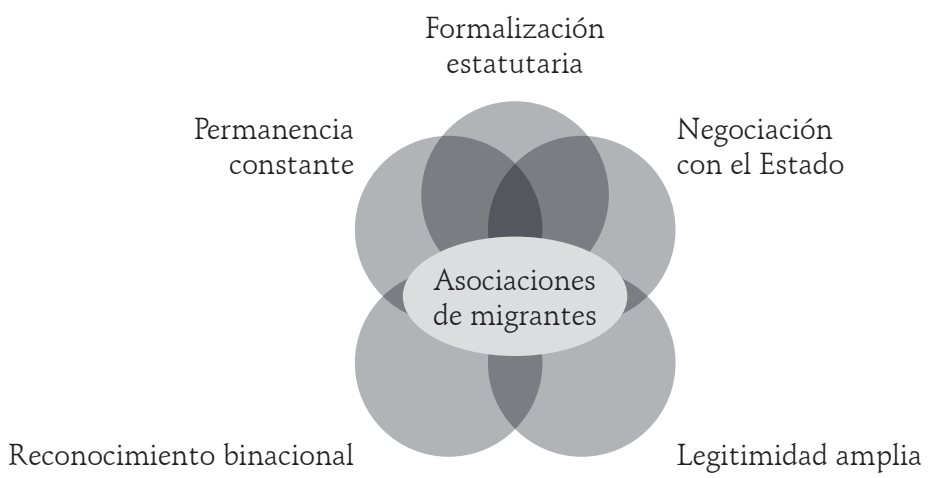


En general, las asociaciones de migrantes se explican como resultado de su actividad e influencia en una región determinada en Estados Unidos. Esto, aunque correcto, es al mismo tiempo parcial. En realidad, estas federaciones mantienen estrechos vínculos entre sí, incluso su desarrollo y desenvolvimiento está íntimamente relacionado. Por ejemplo, algunos comités de pueblos de distintas asociaciones de migrantes zacatecanos derivaron de la influencia que despertó la actividad pionera de la Federación de Zacatecanos del Sur de California. Algunos de sus clubes más fuertes promovieron la organización de otros núcleos lejanos, que provenían de la misma comunidad y, a pesar de la distancia, fueron capaces de coincidir en objetivos y asociarse (véase figura 4). En algunos casos, estas estructuras conservan su cercanía con esta asociación, sin ser miembros de ella. Es decir, la organización regional en Estados Unidos no ha dependido, únicamente, de los inmigrantes existentes en un área urbana específica y, a su vez, no siempre se ha producido la transición de comités de pueblos a la asociación. Inversamente, el impulso que despertaron los líderes de esta Federación de Clubes fue tan lejos que hizo posible la formación de nuevas asociaciones en otras entidades de Estados Unidos. Este proceso también se fue dando a partir de la iniciativa de algunos líderes que residían en Los Ángeles y se fueron a vivir a otras ciudades estadounidenses, tales son los casos de Martín Carvajal y Manuel Arias, quienes fueron pieza clave en la Federación Zacatecana del Norte de Texas. Rafael Hurtado promovió la formación de la Federación Zacatecana en Denver, Colorado. Ricardo López Rizo, Estela Valencia y Rogelio Murillo asistían, de manera frecuente, a las sesiones de trabajo de la Federación del Sur de California y, posteriormente, ayudaron a formar, en el mismo orden, las asociaciones de Oxnard y San José, California, así como Las Vegas, Nevada (Javier González y Javier Cruz Palomino, Entrevista, Buena Park, California, 5 de junio de 2005). Igualmente, cuando Guadalupe Gómez era el Presidente de la Federación Zacatecana del Sur de California, asistió a varias reuniones celebradas en Texas y otras entidades en Estados Unidos, donde expuso la experiencia de esa asociación.

Es decir, las actuales asociaciones han pasado a una etapa de maduración que integra varias organizaciones de segundo nivel en diferentes entidades de Estados Unidos, proceso que viene a dar cuenta de tres aspectos peculiares: i) el establecimiento de varios circuitos poblacionales previos (Durand, 1988); ii) la transición de los clubes a las asociaciones regionales en Estados Unidos, y iii) la conformación de la asociación de asociaciones. En la perspectiva anterior se inscribe lo que intentó ser la Confederación de Clubes de Zacatecanos, que del 14 al 16 de noviembre de 1997 fue constituida, formalmente, en el Consulado Mexicano de Los Angeles (Revista de la FCZUSC, 1997-98), aunque nunca pudo despegar, pero marcó la pauta para la celebración de las convenciones anuales de las organizaciones de zacatecanos en Estados Unidos. Este mismo curso han seguido las Comunidades Unidas Salvadoreñas de Washington y Coalición de Inmigrantes Guatemaltecos en Estados Unidos. 
Pensando en las potencialidades de los agentes sociales, esta iniciativa resulta trascendente porque hay entidades mexicanas que cuentan con varios comités de pueblos en Los Ángeles, Cal., los cuales, para 2004, aún no constituían asociaciones, como eran los clubes de Michoacán, Guanajuato, Distrito Federal, Guerrero, Puebla y Estado de México; en cambio, otros siguen ese mismo camino, ejemplos de ello son los migrantes de Jalisco, Sinaloa, Durango, Nayarit y Oaxaca.

\section{FIGURA 4}

CIRCUITO DE LA ASOCIACIÓN MÁS GRANDE DE MEXICANOS EN EUA, 1999

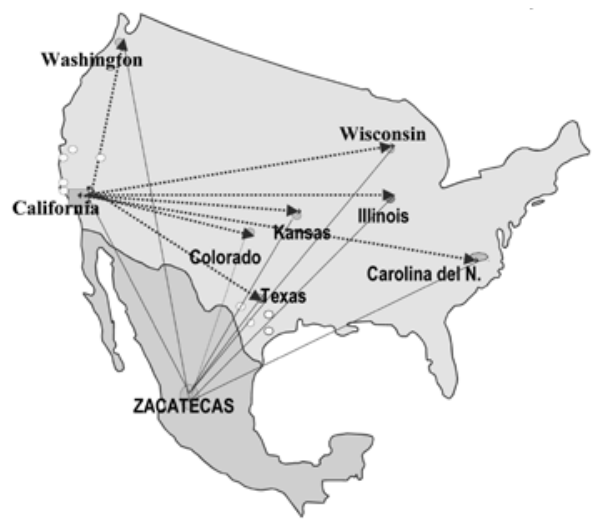

Además de este proceso de maduración, existen distintos grados y modalidades de desarrollo aún más complejos, que solamente se observan en las asociaciones con mayor grado de evolución, mismas que experimentan un desdoblamiento formal e institucional (Moctezuma, 2000a; García Zamora, 2004a) hasta llegar a establecer, claramente, una separación y diferenciación funcional de sus actividades organizativo-comunitarias respecto de la inversión empresarial y participación política (véase figura cinco)

FIGURA 5

MADURACIÓN Y DESDOBLAMIENTO FORMAL

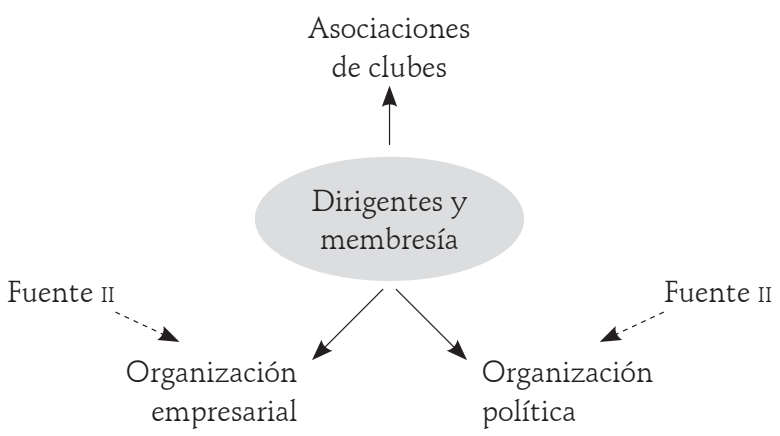


A partir del desdoblamiento formal, al seno de las federaciones de clubes se reconoce la necesidad de diferenciar entre la organización propiamente comunitaria —en sentido amplio (local, regional, estatal)—y la organización empresarial y política. ${ }^{8}$ La actividad comunitaria, aunque sigue siendo central, genera una diversidad de relaciones que hacen posible la organización empresarial y política, encabezada por los líderes de las asociaciones, además de nutrirse externamente, en menor medida, de otros miembros. ${ }^{9}$ Por ejemplo, la Federación Zacatecana de Los Ángeles conforma el Grupo Empresarial de Zacatecanos y el Frente Cívico Zacatecano; por su parte, la Federación Zacatecana de Illinois organiza el Grupo Empresarial de Zacatecanos, y la Federación de Michoacanos configura el Frente Binacional Michoacano. Un aspecto característico de este desdoblamiento consiste en que, esta diferenciación, reduce las tensiones y pone a salvaguarda la organización estrictamente comunitaria. A partir de esta compleja fórmula, cada cual ha conseguido su reconocimiento y autonomía. El caso del Frente Cívico Zacatecano ha ido más lejos, hasta alcanzar niveles de participación claramente binacionales, cuya incidencia del lado mexicano no se le puede reducir a la participación en los procesos electorales o a la reforma electoral, sino a la búsqueda de una propuesta de alto impacto donde el Frente es pieza clave de los procesos democratizadores y de desarrollo de su entidad.

Los procesos de institucionalización y desdoblamiento formal han servido, asimismo, para la transmisión de experiencias. La Federación de Zacatecanos en Los Ángeles estableció un fondo de becas en beneficio de estudiantes sobresalientes y de escasos recursos, tanto en Estados Unidos como en Zacatecas, a través de donativos provenientes de empresarios diversos, experiencia que hizo suya la Federación de Zacatecanos en Illinois; a su vez, esta última fue la primera en crear un grupo juvenil de estudiantes que sirven de apoyo y respaldo a las actividades de su organización, iniciativa que imitó, inmediatamente, la Federación de Los Ángeles y que, como parte del proceso de desdoblamiento formal e institucional,

\footnotetext{
${ }^{8}$ Como lo reconocen los resolutivos de la Segunda Convención de Organizaciones de Zacatecanos: «Una de las conclusiones más importantes de esta Convención es que busquemos conservar la unidad respetando la naturaleza comunitaria de nuestras organizaciones. Esto quiere decir que no se debe partidizar el trabajo que realizamos. Por ello, quienes tomen iniciativas de tipo político, reconociendo que tienen derecho, este debe hacerse en estructuras e instancias de otra naturaleza» (Resolutivo de la Segunda Convención Anual de Organizaciones de Zacatecanos en los Estados Unidos, Chicago, Illinois, 21 de julio de 2001).

${ }^{9}$ Es correcto que estas organizaciones se involucren políticamente, pero lo que resulta muy perverso es que se partidicen y que reproduzcan la cultura clientelar, así como corporativa, de la política mexicana. Cuando esto sucede, se fragmentan y pierden su sentido comunitario. Asimismo, se les ocasiona un enorme daño cuando el gobierno intenta mantener el control corporativo sobre ellas. Por supuesto, ellos hacen política, pero lo hacen como sociedad civil. Es posible, también, que vayan más lejos y terminen involucrándose en calidad de militantes y simpatizantes de algún partido político; en este caso, lo recomendable es que separen la vida estrictamente comunitaria respecto de la militancia política.
} 
se mantiene igual que en los casos anteriores, como una instancia con cierta autonomía a partir de su particularidad.

Un aspecto que comparten todas las asociaciones es lo referente a la realización de obras comunitarias que reciben financiamiento a través de las remesas colectivas, formando parte de los programas gubernamentales de los tres niveles de gobierno. En esto hay algunas diferencias, como reconoce la Federación de Clubes Unidos de Zacatecanos en Illinois, pues para ellos es muy importante la inversión en obras sociales y comunitarias auténticamente filantrópicas, como la construcción de asilos, la circulación de panteones, el apoyo técnico a escuelas públicas que no siempre forman parte de los programas gubernamentales. Existen, además, muchas otras acciones de esta naturaleza que los migrantes emprenden sin el acompañamiento del Estado.

Se encuentran, asimismo, niveles de participación excepcionales, en los que se involucran las asociaciones y las organizaciones políticas de los migrantes que han alcanzado el mayor grado de madurez, mostrando que son capaces no sólo de diseñar e implementar determinadas estrategias entre su membresía, sino también de asistir o asesorar, merced a su experiencia, a otros migrantes para que organicen sus clubes, además de promover iniciativas pioneras en varios campos. Por esta vía se desarrolla el sujeto migrante, se trasmiten las experiencias y se corrigen los errores, al tiempo que se construyen lazos así como compromisos mutuos. La Federación de Clubes de Zacatecanos del Sur de California es pionera en los programas Uno por Uno, Dos por Uno y Tres por Uno. Su experiencia ha sido clave para que este programa se extienda a otras asociaciones. En la actualidad, gracias al rol de sus líderes, el Tres por Uno se ha convertido también en un programa nacional. ${ }^{10}$ En este campo, la federación zacatecana cuenta con una rica experiencia que ha compartido con migrantes de El Salvador y otros países, cuyos encuentros son cada vez más frecuentes. Recientemente, el 12 de octubre de 2005 se suscribió un convenio de colaboración con First Data y su subsidiaria, Western Union, la que aportará 1.25 millones de dólares, de los cuales, 250 mil se canalizarán al estado de Zacatecas con el objetivo de promover un fondo "Cuatro por Uno» (véase http:www.fedreracionzacatecana.org/).

Asimismo, en el aspecto político, el Frente Cívico Zacatecano, en alianza

\footnotetext{
${ }^{10}$ Se trata de un programa diseñado por las asociaciones de los migrantes zacatecanos para invertir en obras sociales, recreativas y de infraestructura en las comunidades de origen, mediante el cual por cada dólar que aportan, los gobiernos federal, estatal y municipal aportan otro; por esa vía, a partir de 1999 se constituye el Tres por Uno. Sus orígenes se remontan a 1986, cuando el gobierno del estado financiaba con un dólar por otro proveniente de los migrantes, lo cual se conoció como Programa Uno por Uno; más tarde, en 1993, con el financiamiento respectivo del gobierno federal se transformó en Programa Dos por Uno, hasta llegar a la versión actual. En Zacatecas, en 2003, a través del Tres por Uno se invirtieron alrededor de 20 millones de dólares, los cuales abarcan cientos de obras.
} 
con el AfL-Cio, encabezó la defensa, en California, de las licencias de manejo y, por su cuenta en Zacatecas, la promoción exitosa de la primera Iniciativa de Reforma a la Constitución Política de Zacatecas en materia de derechos políticos electorales, vigente desde el 1 de octubre de 2003.

Por su parte, el Frente Indígena Oaxaqueño Binacional es pieza importante, en Estados Unidos, para el establecimiento de un programa de defensoría legal que traduce las lenguas étnicas al inglés; ésta y otras medidas contribuyen a abrir el camino para la unificación y superación de las diferencias entre las comunidades indígenas, así como la participación en alianzas electorales para la elección de legisladores en Oaxaca. Esta organización, igualmente, cuenta con el Centro Binacional para el Desarrollo Oaxaqueño que promueve proyectos comunitarios (véase http//www.red.indigenanet/organinteg/1fiob.html).

El Frente Indígena Oaxaqueño Binacional y la Federación de Clubes de Zacatecanos del Sur de California promueven un programa, inédito en su tipo, para la capacitación institucional y de desarrollo del liderazgo, mismo que cuenta con el auspicio de la Fundación Rockefeller y el respaldo de investigadores de la Universidad del Sur de California, el Colegio de la Frontera Norte y el Doctorado en Estudios del Desarrollo de la Universidad Autónoma de Zacatecas. A este esfuerzo han sido llamados a participar líderes de otras asociaciones del país. Finalmente, la Federación de Clubes Zacatecanos, en coordinación con la Universidad Autónoma de Zacatecas, ha promovido la creación del Centro de Apoyo para el Desarrollo Empresarial Comunitario con financiamiento de la Inter-American Foundation (IAF), cuyos objetivos son la evaluación de solicitudes de proyectos de inversión de capital migrante, la capacitación técnica de personal, la promoción de una cultura empresarial y la asistencia técnica a los posibles inversionistas.

FIGURA 6

EL CICLO DE FORMACIÓN DE LAS ASOCIACIONES

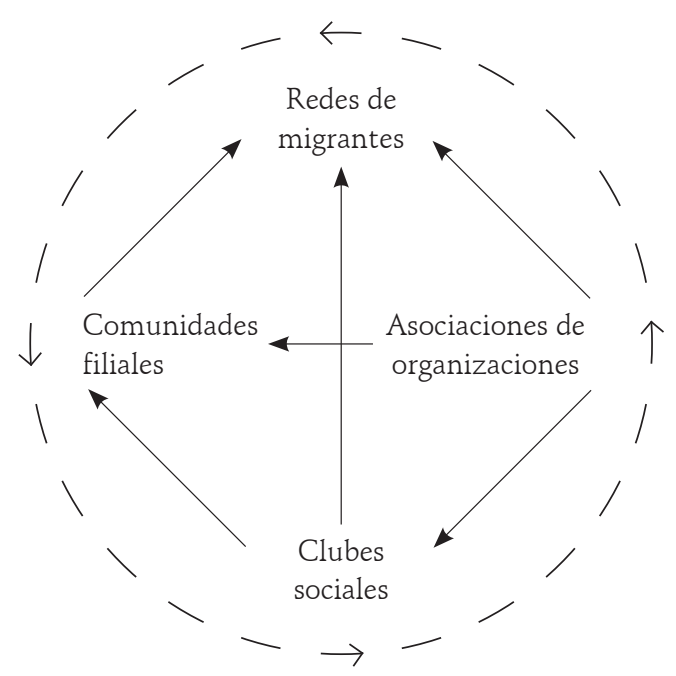


En una panorámica de conjunto -y siguiendo su lógica-, la organización de migrantes presenta un ciclo abierto, cuya espiral inicia con las redes sociales, luego éstas evolucionan hacia las llamadas comunidades filiales; más tarde dan origen a los comités de pueblos - aunque no siempre sucede así-y, finalmente, hacen posible la asociación de migrantes. En la figura 6, el sentido de las flechas indica el curso probable que suele seguir el ciclo, sin embargo, también hay que resaltar que, en cada momento, la espiral va avanzando y da origen a relaciones reticulares cada vez más complejas y superiores. Sin que esto sea reducido a una secuencia sucesiva, cuando se llega a la asociación de organizaciones de migrantes, el ciclo se hace más complejo y se desenvuelve sobre sí mismo, de tal manera que la asociación va generando una fuerza centrípeta sobre la cual comienza a girar la práctica de estas organizaciones.

\section{ASOCIACIONES DE MIGRANTES Y}

ESTADO MEXICANO

Así como las asociaciones de migrantes desarrollan distintos grados de organización, también es posible localizar diversas formas de vinculación de estas estructuras sociales con la sociedad civil, los partidos y el Estado, tanto del país de origen como de destino.

Al concentrar la atención sólo en el país de origen, hemos encontrado varias modalidades y opciones posibles: aislamiento/invisibilidad, displicencia/cooptación, autonomía/tolerancia o autonomía/confrontación.

El aislamiento e invisibilidad es la manifestación inicial de la relación de las primeras asociaciones de migrantes con el Estado mexicano. Todas estas asociaciones pasaron por tal proceso, el cual abarca varias décadas y es expresión de la indiferencia política del Estado mexicano hacia los migrantes. Bajo esta modalidad, para el Estado mexicano, los migrantes son invisibles, no tienen importancia y no forman parte de la agenda de negociación con el gobierno de Estados Unidos. Esta práctica abarca desde la formación de las primeras asociaciones, en 1960, hasta 1988, año en el que las campañas políticas y la disputa electoral por la Presidencia de la República permitieron mostrar su importancia social y política, así como su influencia en los destinos de México (véase figura siete).

Se trata de una actitud difícil, en la cual, el vínculo más estrecho de estas asociaciones se produce a nivel local, con las autoridades municipales, la Iglesia y la escuela. Para los migrantes, la campaña presidencial de 1988 constituye un hito que rompe con un pasado de indiferencia por parte del Estado mexicano.

La segunda expresión de relación, con el Estado mexicano, es la displicencia y cooptación, impulsada a través del reconocimiento de los comités de pueblos por los consulados mexicanos, donde el Consulado de Los Ángeles, Cal., destaca por sus logros en este ámbito. A partir de entonces, el Estado modifica su actitud y 
diseña varios programas de vinculación con este importante sector de connacionales, tales como el Programa para las Comunidades de Mexicanos en el Extranjero, Programa Paisano, Oficinas Estatales de Atención a Migrantes, Programa Dos por Uno y Tres por Uno; además de las reformas constitucionales, como el reconocimiento de la no pérdida de la nacionalidad mexicana y el derecho a votar en las elecciones federales sin la condición de residir en un distrito electoral determinado, aspecto que hasta junio de 2005 pudo concretarse en la reforma al Código Federal de Instituciones y Procedimientos Electorales (COFIPE), en materia de derechos político-electorales.

FIGURA 7

MODALIDADES DE RELACIÓN DE LAS

ASOCIACIONES MIGRANTES CON EL ESTADO

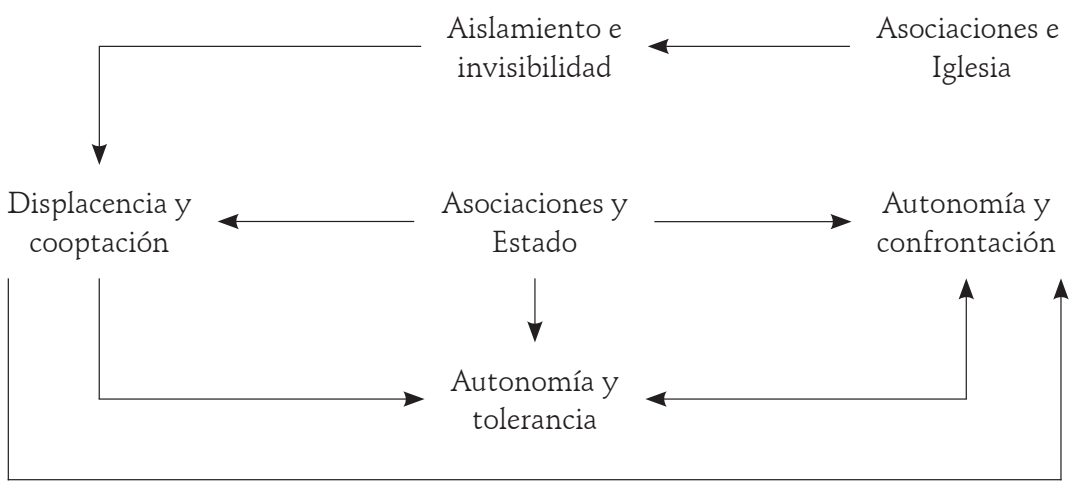

A diferencia de las primeras asociaciones de los setenta y ochenta, los clubes que, a principios de la década de los noventa, fueron formados y organizados por los consulados mexicanos se inscribieron, de manera directa, en esta segunda caracterización, a ello se refieren quienes señalan la reproducción del corporativismo político propio del sistema político mexicano. De hecho, el presidente Carlos Salinas de Gortari se dio cuenta que los migrantes residentes en Estados Unidos no debían ignorarse ya que, durante la campaña electoral presidencial, habían mostrado una actitud crítica y de simpatía con la oposición. Para algunos especialistas, se trata de un neocorporativismo que cuenta con la docilidad de los connacionales organizados, hecho que desde la academia lleva, equivocadamente, a desacreditar los programas de inversión social de los migrantes y a concentrar la atención en el monto de las remesas colectivas, olvidando el conjunto de repercusiones que, en el terreno de las prácticas sociales, traen consigo y que son más importantes que las mismas remesas.

En el terreno político, esta experiencia se corresponde, en el tiempo, con la inexistencia de propuestas alternas - y menos de propuestas alternativas al régi- 
men-, ya que Salinas difunde, con bastante éxito, la inviabilidad de las opciones populistas y nacionalistas frente al proyecto neoliberal que él encarna. Aunque pronto desaparece el encanto y se hacen visibles las contradicciones de la clase política, al tiempo que surge un sistema competitivo de partidos; pero, de pronto, se exacerba la crisis de legitimidad del sistema político presidencialista por los resultados electorales dudosos y las muertes no aclaradas de algunos de sus dirigentes destacados, crece la influencia y pluralidad de los gobiernos locales y estatales que proceden de distintas tendencias partidistas, se modifican las normas electorales y se da mayor certidumbre en la competencia electoral, a la vez que se transforma la imagen de los migrantes y binacionales en la sociedad, así como en los círculos oficiales. Además, aumentan las presiones que, desde distintos ángulos internos y externos, viene sufriendo el régimen mexicano para su democratización, al tiempo que crece la participación cívica y política de las organizaciones sociales de los migrantes, exigiendo el ejercicio de sus derechos políticos (Hazán, 2001).

En este proceso, se producen experiencias muy peculiares, como lo muestra una de las organizaciones de migrantes oaxaqueños (Frente Indígena Oaxaqueño Binacional) que se resistió a ser absorbido y, aunque en todo este periodo participa en el destino de las comunidades de Oaxaca, se niega a establecer relaciones de cooptación con el Estado mexicano y el gobierno de su entidad.

La tercera y cuarta expresiones son las de autonomía/tolerancia o autonomía/confrontación. Ambas se combinan y son experimentadas, simultáneamente, por una misma organización. La Federación de Clubes de Zacatecanos del Sur de California vive, en 1998, los procesos de autonomía como una ruptura violenta con el viejo régimen emanado del PRI. Más tarde, cuando el PRD gana las elecciones a la gubernatura de la entidad, inicia una breve fase de autonomía con tolerancia, pero inesperadamente se torna en confrontación virulenta. Mientras esto sucede, la Federación de Clubes Unidos de Zacatecanos en Illinois logra mantener una relación de autonomía sin conflicto y lo mismo hace la Federación del Norte de Texas. En el resto de las asociaciones de migrantes zacatecanos se muestra una adhesión incondicional al gobierno de Zacatecas; para los migrantes, este proceso resulta difícil de enfrentar en unidad de acción. Por tanto, es gracias a la extensa fuerza, poder y legitimidad con que cuenta la Federación de Clubes del Sur de California lo que explica que, a pesar de los duros embates del gobierno del estado, esta asociación logre respaldar la primera iniciativa de reforma constitucional sobre derechos políticos ciudadanos, cuya propuesta provino del Frente Cívico Zacatecano.

La apreciación que se tiene de los oaxaqueños es un tanto distinta. En este caso, la exclusión política y cultural de los indígenas a que han sido sometidos, secularmente, por el Estado mexicano, los ha conminado a mantener distancia respecto del gobierno de su entidad, lo que aunado a su naturaleza indígena los hace más proclives y cuidadosos de su autonomía, cuyo habitus (Bourdieu, 1991), basado en el sistema de cargos, los conduce, de manera frecuente, al ejercicio de las prácticas extra y transterritoriales, sin que esto requiera de una reglamenta- 
ción en el terreno de la legislación local. Un caso intermedio es el de las asociaciones de migrantes michoacanos.

Estos cuatro tipos de relaciones con el Estado, aún sin ser homogéneas ni lineales, dan cuenta del proceso de reconocimiento formal de las autoridades mexicanas hacia los migrantes, al tiempo que éstos van negociando su relación y aumentando su presencia más allá del ámbito local. Ambos actores se han ido dando cuenta que la mejor forma de relacionarse es bajo un sistema de respeto y autonomía; sin embargo, también hay que reconocer que, tanto entre los líderes de las asociaciones de migrantes como en el Estado, persisten resabios de la cultura política del viejo régimen presidencialista. Esto constituye una fuente de conflicto latente entre su membresía, sobre todo cuando, desde su interior, existen líderes que comparten este tipo de relación con el Estado.

\section{BINACIONALIDAD DE LAS \\ ASOCIACIONES}

Para la mayoría de los estudiosos, las prácticas de los migrantes siguen centradas en México. Existe, incluso, la exageración de que las asociaciones se están olvidando de tomar iniciativas para su empoderamiento y visibilidad en Estados Unidos. Esto no es del todo cierto. Las asociaciones, en determinadas coyunturas, han estado muy activas en Estados Unidos (Escala-Rabadán, 2004), aunque esta actividad, como ocurre en toda organización, no puede ser sostenida de manera permanente. Existe un factor condicionante y limitativo de la participación política: la naturaleza no partidista y no lucrativa de las organizaciones comunitarias. Participan en política, pero lo hacen sólo en términos generales, es decir, como una práctica no partidista o como actividad defensora de los derechos adquiridos por los inmigrantes, ya sean estos sociales, económicos, culturales, étnicos (Escala-Rabadán, 2004), en coincidencia con otros grupos sociales y onG. Se trata, por tanto, de una política social que nadie puede objetar por ser de carácter general. Sobre esta lógica se gana en legitimidad para movilizar su membresía para la obtención de la ciudadanía estadounidense, como sucedió en reacción a la Propuesta 187 que impulsó Peter Wilson en 1994. Igualmente, a través de grandes movilizaciones, estas organizaciones hicieron suyas las demandas de regularización de los inmigrantes indocumentados y la expedición de licencias de manejar (Javier González, Entrevista, 9 de enero de 2003). En otro tenor, un caso desconocido fue, también, la toma de las oficinas del Consulado Mexicano por un numeroso grupo de mexicanos en 1994, cuando el Ejército Mexicano estaba bombardeando las comunidades indígenas del Ejército Zapatista de Liberación Nacional (EZLN) (José González, Entrevista, 9 de enero de 2003). Sin embargo, estas acciones, condicionadas al impulso de una demanda de política general, han venido encontrando otras fórmulas flexibles de mayor compromiso político. Como parte del complejo 
proceso de desdoblamiento formal e institucional, el Frente Cívico Zacatecano se ha involucrado, militantemente, en las campañas de Lou Correa —originario de Calera, Zacatecas-y Linda Sánchez, ambos asambleístas por California; Miguel Pulido, alcalde de Santa Ana; Jesse Loera, alcalde de Norwalk; Gray Davis y Cruz Bustamante, gobernador y vicegobernador de California; además de Loreta Sánchez y Grace Napolitano, congresistas nacionales. Esta misma organización política también ha apoyado a políticos republicanos como Lee Vaca, sheriff de Los Ángeles, además de formar parte del Comité de AFL-CIO en la campaña para la regularización de los inmigrantes, al tiempo que han facilitado los encuentros entre los gobernadores de California y Zacatecas (Guadalupe Gómez, Javier Cruz Palomino, Javier González y José Hernández, Entrevistas, Los Ángeles, Cal., 10 de marzo de 2002). Rosalva Ruiz, ex presidenta de la Federación de Clubes Unidos de Zacatecanos en Illinois, ha hecho lo propio con respecto a Luis V. Gutiérrez - congresista por el 4to. distrito electoral de Illinois-y Edward Burke, consejal del distrito 14 de la ciudad de Chicago, además de servir como intermediaria para encuentros entre el gobernador de Zacatecas y el alcalde de Chicago.

En la reciente elección del alcalde de Los Ángeles, Antonio Villaraigosa, aunque el Frente Cívico Zacatecano no se involucró en la campaña electoral como organización, sí lo hicieron algunos de sus miembros, como Maricela Talamantes y Guadalupe Rodríguez. Al interrogarles por qué el Frente Cívico Zacatecano no impulsó la campana de Villaraigosa, la respuesta fue que muchos de sus principales líderes no son residentes de Los Angeles, sino de otros condados aledaños, como Norwalk, Santa Ana y Lynwood (Javier González y Javier Cruz Palomino, Entrevista, Buena Park, California, 5 de junio de 2005). Estas y otras acciones muestran que este sujeto migrante avanza, binacionalmente, de manera sostenida hacia su empoderamiento, además, la clase política de las entidades estadounidenses, que cuentan con numerosos porcentajes de latinos y mexicanos, poco a poco reconoce la existencia de un electorado real y potencial que ha de ser incorporado, así como tomado en cuenta, en sus plataformas electorales.

Finalmente, otro aspecto en el que las asociaciones incursionan, con cierto éxito, es en el involucramiento de los jóvenes de segunda generación:

[...] un grupo de jóvenes reunidos por nuestra herencia zacatecana nos hemos consolidado para fomentar el conocimiento de nuestra cultura, el liderazgo, la solidaridad y el servicio comunitario para darle empoderamiento a nuestra comunidad. Aspiramos a servir a nuestra comunidad como una red de información y servicio de áreas como: educación, fomento cultural, ayuda pública y participación cívica (Revista de la FCZUSC, 2002-2003: 68).

En realidad, los resultados más interesantes, a favor de esta tendencia, coinciden con el hecho de que algunos dirigentes de clubes de migrantes zacatecanos son jóvenes que llegaron a Estados Unidos en los primeros años de vida o nacieron 
en ese país y, ahora, cuentan con formación universitaria, como Reina Reyes, presidenta de la Federación de Florida; Erika González, presidenta de la Federaci $\square$ n de Orange; Martha Jiménez, presidenta del Club Hermandad Las Animas; Ramón Velasco, presidente del Club Regionales de Tayahua; Suliana González, presidenta del Club Social Chacuiloca; Denise González, graduada de la Universidad de Berkeley y representante del Grupo Juvenil de California, y Zenia Ruíz, egresada de la Universidad del Sur de California y pionera del Grupo Juvenil de Illinois. En conjunto, se plantean respaldar las acciones y actividades de los clubes (Revista de la FCZUSC, 1999-2000 y 2000-2001). Estos aspectos, aunque no se les puede generalizar, se agregan a los ya señalados, los cuales vienen a cuestionar, radicalmente, muchas de las imágenes simplistas que teníamos sobre la membresía y la práctica de los mexicanos organizados que residen en el extranjero.

\section{CONCLUSIÓN}

Al colocar a las asociaciones de los clubes en el centro del análisis parece como si las primeras estructuras sociales que les han dado origen dejaran de existir, pero no es así. Las redes sociales surgen como producto de la migración, pero, con el tiempo, dan origen, en un mismo espacio o en espacios contiguos, a los asentamientos de migrantes o las llamadas comunidades filiales, donde la vida comunitaria trasnacional resurge a partir de los hogares de los migrantes establecidos, particularmente por el papel cultural que desempeña la mujer. Una vez que esto sucede, la migración circular, aunque paralelamente continúa, evoluciona sobre la base de la existencia de los núcleos de migrantes establecidos. Empero, como reacción inversa, la migración lleva a buscar nuevas fórmulas de pertenencia y membresía para con la comunidad de origen. Por tanto, si en el extranjero se reproducen las relaciones entre los migrantes de una misma comunidad —y de éstas pasan a los comités de pueblos así como asociaciones-, constituyen modalidades y niveles de organización cualitativamente distintos en donde lo local, regional y nacional se recrea, reconfigura, imagina e inventa hasta asumir el compromiso de la participación activa.

Una vez que, en Estados Unidos, una entidad cuenta con multitud de comunidades filiales, aumenta la probabilidad de que surjan los comités de pueblos, que constituyen una primera forma de organización que antecede, en el tiempo, al interés mostrado por el Estado mexicano y expresa, con nitidez, la lógica de la política migratoria en ese renglón. Sobre estas condiciones surgen, también, las primeras asociaciones de clubes, que a partir de las relaciones de convivencia comunitaria e identidad cívica sientan las bases para el desarrollo formal y desdoblamiento de su organización.

La asociación, como estructura articuladora de los comités de pueblos, posibilita el mantenimiento de relaciones horizontales y verticales de sus miembros, proceso a partir del cual se extienden y enriquecen las experiencias hasta 
constituir una institución compleja, cuyo desdoblamiento formal hace posible el desarrollo de prácticas paralelas y diversas que buscan evitar conflictos sobre su naturaleza comunitaria, mostrando, asimismo, al gobierno mexicano las posibles opciones para promover programas de acompañamiento con base en la especificidad de los sujetos migrantes. Aún así, las asociaciones de clubes, constituyendo las estructuras superiores, siguen alimentándose de las redes sociales, las comunidades filiales y los comités de pueblos (véase figura ocho).

FIGURA 8

EL MIGRANTE COLECTIVO,

UN PROCESO DE PARTICIPACIÓN Y COMPROMISO DIFERENCIADO

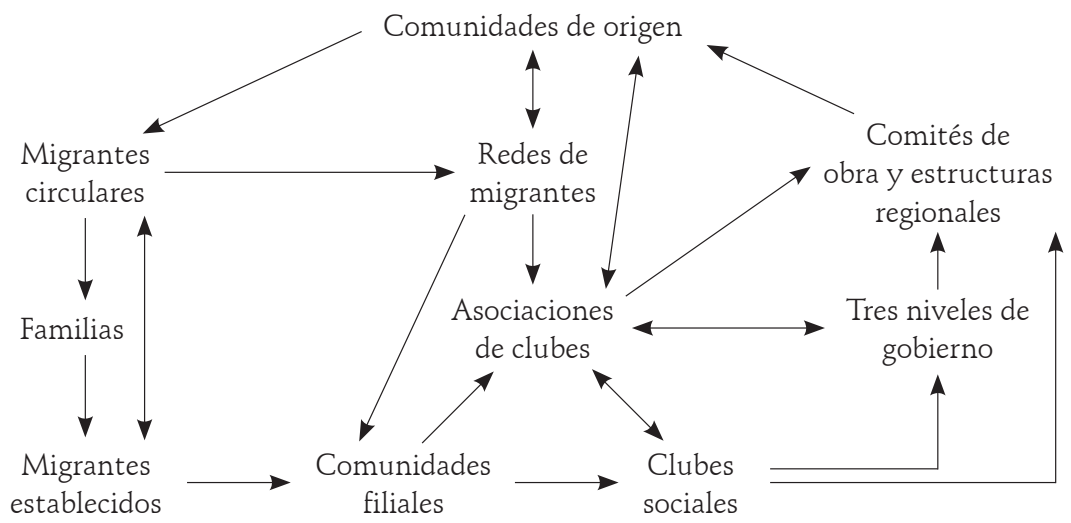

En las asociaciones de clubes, las redes sociales de los migrantes individuales se mantienen, pero ahora forman parte de la vida comunitaria y organizativa; se trata, por tanto, de relaciones cuyo capital social se va incrementando y modificando a partir de los sujetos. Asimismo, las comunidades y la vida comunitaria transnacional siguen alimentando, reproduciendo y reestructurando la cultura matriótica, pero, con las asociaciones, esta práctica viene a fortalecer a los comités de pueblos, es decir, las relaciones de identidad de las comunidades filiales evolucionan, también, a partir de las relaciones de membresía de las asociaciones. Este proceso es, sin embargo, más complejo, ya que el individuo conserva distintos niveles de participación activa.

Asimismo, las asociaciones mantienen una relación directa o mediada, a través de los comités de pueblos, con la comunidad, los tres niveles de gobierno y, de manera estrecha, con los comités de obra en las comunidades de origen. Este tipo de vinculación se refiere a la existencia de procesos articulados, de no ser así destacaría la separación de ambas entidades sociales negando la simultaneidad de sus prácticas donde los sujetos actúan más allá de los espacios territoriales inmediatos. Al prescindir de estos procesos, el análisis corre el riesgo de experimentar un retroceso, como sucede en algunas versiones simplistas del transnacionalismo, 
además de presentar los resultados de las asociaciones, respecto de la comunidad de origen, como una lucha de intereses encontrados, emulando trivialmente una «lucha de clases», cuando, las relaciones comunitarias trasnacionales, lo que permiten es abordar estos temas a partir de lo que ellas comparten, lo que de ninguna manera implica la negación de contradicciones que se derivan de las mismas relaciones sociales en que se desenvuelven los sujetos, incluyendo las relaciones sociales específicas de la comunidad de origen. Estas contradicciones, además, se manifiestan en el curso que siguen las familias en lo que corresponde a las relaciones de poder y de género, las cuales chocan con la vida y la visión tradicional.

Finalmente, una asociación sólo consigue ayudar a organizar y brindar asesoría a otra asociación sólo si cuenta con un alto reconocimiento y confianza. Esto se logra cuando la legitimidad de una asociación se asocia a la madurez, experiencia y reconocimiento — nacional y binacional — de sus miembros y dirigentes, justo esto es lo que representa la Federación de Clubes de Zacatecanos del Sur de California.

\section{BIBLIOGRAFÍA}

BASCH, Linda, Nina Glick Schiller y Cristina Szanton Blanc (1994), Nations Unbound: Transnational Proyects, Poscolonial Predicaments and the Desterritorialized Nation-State, New York, Gordon and Breach Publishers.

BHABHA, Homi K. (1990), "Dissemination: time, narrative and the margins of the modern nation", en Homi K. Bhabha (ed.), Nation and Narration, New York, Routledge, pp. 291-322.

Bourdieu, Pierre (1991), El Sentido Práctico, Madrid, Taurus Editores.

Brubaker, William Rogers (1990), "Immigration, Citizenship, and the NationState in France and Germany, a Comparative Historical Analysis», en International Sociology, 5(4), Stanford University.

Carreras de Velasco, Mercedes (1974), Los mexicanos que devolvió la crisis 1929-1932, México, Secretaría de Relaciones Exteriores, Tlatelolco.

Dore, Carlos, José Itzigson, Esther Hernández, Obed Vázquez (2003), «Cartografía del transnacionalismo dominicano: amplias y estrechas prácticas transnacionales», en Alejandro Portes, Luis Guarnizo y Patricia Landolt (coords.), La Globalización desde Abajo: Transnacionalismo Inmigrante y Desarrollo. La experiencia de Estados Unidos y América Latina, FLACso, México, Miguel Ángel Porrúa.

Durand, Jorge (1988), "Circuitos migratorios», en Thomás Calva y Gustavo López Castro (coords.), Movimientos de población en México, Zamora, El Colegio de Michoacán.

(1994), Más Allá de la Línea. Patrones migratorios entre México y Estados Unidos, México, Consejo Nacional para la Cultura y las Artes. 
EsCAlA-RABADÁn, Luis (2004), «Migración y formas organizativas en los Estados Unidos: los clubes y federaciones de migrantes mexicanos en California», en Guillaume Lanly y Basilia Valenzuela (comps.), Clubes de Migrantes Oriundos Mexicanos en los Estados Unidos: la politica trasnacional de la nueva sociedad migrantes, Universidad de Guadalajara.

Espinosa,Víctor M. (1998), El Dilema del Retorno. Migración, Género y Pertenencia en un contexto transnacional, México, El Colegio de Michoacán, El Colegio de Jalisco.

Federación de Clubes de Zacatecanos Unidos del Sur de California, revista, varios números: 1992, 1993, 1994-95, 1995-96, 1997-98, 1998-99, 1999-2000 y 2000-2001.

Fox, Jonathan y Gaspar Rivera-Salgado (2004), «Introducción», en Jonathan Fox y Gaspar Rivera-Salgado (coords.), Indígenas Mexicanos Migrantes en los Estados Unidos, México, Miguel Ángel Porrúa.

García Zamora, Rodolfo (2004a), "Los retos de las organizaciones de migrantes mexicanos en Estados Unidos: el caso de las federaciones de clubes zacatecanos», en Estudios centroamericanos, julio-agosto, El Salvador, Universidad Centroamericana «José Simeón Cañas» (ECA).

(2004b), «Migración internacional y desarrollo local: una propuesta binacional para el desarrollo regional del sur de Zacatecas», en Raúl Delgado Wise y Margarita Fabela (coords.), Nuevas tendencias y desafíos de la migración internacional México-Estados Unidos, México, Miguel Ángel Porrúa.

Gamio, Manuel (1930), Número, procedencia y distribución de los emigrantes mexicanos en los Estados Unidos, México, Talleres Gráficos Editorial, Diario Oficial.

GoldRING, Luin (1997), "El Estado mexicano y las organizaciones transmigrantes: خ̀reconfigurando la nación, ciudadanía y las relaciones entre Estado y sociedad civil?», en XIX Coloquio de Antropología e Historias Regionales, El Colegio de Michoacán, octubre 22-24.

GonzÁlez y González, Luis (1986), «Suave matria», en Nexos, no. 108, México, diciembre.

GonzÁlez, Carlos (1995), "La organización de los inmigrantes mexicanos en Los Angeles: la lealtad de los oriundos», en Revista Mexicana de Política Exterior, no. 46.

Hannerz, Ulf (1996), Transnational Connections: Culture People, Londres, Routledge. HazAn, Miryam (2002), «Políticas de incorporación política y actividades de inmigrantes: los casos de colombianos y mexicanos en los Estados Unidos», en Ensayo inédito, Texas, University of Texas at Austin.

Honey, Rex y Okafor Stanley (1998), Hometown Associations. Indigenous Knowledge and Development in Nigeria, London, Intermediate Technology Publications.

ITZIGSOHN, José (2000), «Immigration and the boundaries or citizenship: the institutions of immigrants political transnationalism", en International Migration Review, vol. Xxxiv, no. 4. 
LANDolt, Patricia (2001), «Salvadoran Economic Transnationalism: Embedded Strategies for Household Maintenance, Immigrant Incorporation and Entrepreneurial Expansion», en Global Networks, 1, pp. 217-42. , Autler y Sonia Lilian y Baires (2003), «Del hermano lejano al hermano mayor: la dialéctica del trasnacionalismo salvadoreño», en Alejandro Portes, Luis Guarnizo y Patricia Landolt (coords.), La Globalización desde Abajo: Trasnacionalismo Inmigrante y Desarrollo. La experiencia de Estados Unidos y América Latina.

LANLY, Guillaume y Hamann Volver (2004), «Solidaridades trasnfronterizas y la emergencia de una sociedad civil transnacional: la participación de dos clubes de migrantes en el desarrollo local del occidente de México», en Guillaume Lanly y Basilia Valenzuela (comps.), Clubes de migrantes oriundos mexicanos en los Estados Unidos: la política trasnacional de la nueva sociedad migrantes.

LeVITT, Peggy y Nina Glick Schiller (2005), «Perspectivas transnacionales sobre la migración", en International Migration Review.

Moctezuma L., Miguel y H. Rodríguez Ramírez (2000a), «Programas Tres por Uno y Mi Comunidad. Evaluación con migrantes zacatecanos y guanajuatenses radicados en Chicago, Ill., y Los Angeles, Ca.», en Informe de Investigación, Zacatecas.

(2000b), «La organización de los migrantes zacatecanos en los Estados Unidos», en Cuadernos Agrarios, México, Nueva Época, no. 19-20.

(2000c), «El circuito migrante Sain Alto, Zac.-Oakland, Ca.», en Comercio Exterior, México, vol. 50, no. 5, mayo.

(2002), «Los migrantes mexicanos en los Estados Unidos y la inversión productiva en México», en Migraciones Internacionales, vol. 1, no. 3, El Colegio de la Frontera Norte, julio-diciembre.

(2004b), «La experiencia política binacional de los zacatecanos residentes en Estados Unidos. El caso del Frente Cívico Zacatecano», en Raúl Delgado Wise y Margarita Fabela (coords.), Nuevas Tendencias y Desafíos de la Migración Internacional México-Estados Unidos.

PORTES, Alejandro, Luis Eduardo Guarnizo y Patricia Landolt (2003), «El estudio del transnacionalismo: peligros latentes y promesas de un campo de investigación emergente», en Alejandro Portes, Luis Guarnizo y Patricia Landolt (coords.), La globalización desde abajo: transnacionalismo inmigrante y desarro11o. La experiencia de Estados Unidos y América Latina.

Rouse, Roger Christopher (1994), "Mexican migration and the social space of postmodernism», en Diáspora, 1(1), La Jolla, San Diego Center for U.S. Mexican Studies, University of California.

SANTibáÑEz, Enrique (1930), Ensayo acerca de la inmigración mexicana en los Estados Unidos, San Antonio, Texas.

SMITH, Michael y Luis Eduardo Guarnizo (1999), "The locations of transnationa- 
lism», en Michael Peter Smith and Luis Eduardo Guarnizo (eds.), Transnationalism from Below, New Brunswick, New Jersey, Transaction Publishers.

TAYlor, Paul S. (1929), Mexican labor in the United States: migration statistic, Berkeley, University of California Press, vol. vi, no. 3.

(1930), Mexican labor in the United States, Dimmit Country, Winter Garden District South Texas, Berkeley, University of California Press, vol. vi, no. 5. (1931), Mexican labor in the United States, Bethelhei, Pennsylvania, University of California Press, vol. vil, no. I.

(1933), A spanish-mexican peasant community. Arandas in Jalisco, Mexico, University of California Press.

Waldinger, Roger y David Fitzgerald (2003), "Trasnationalism in Question», Ponencia, CCIS, Universidad de California, San Diego, 18-24 de junio.

Zaldívar Ortega, J. (1993), El Momento en Los Angeles, enero 9.

Zamudio, Patricia (2004), "La ocasión de preludio: organizaciones de migrantes veracruzanos en los Estados Unidos», en Guillaume Lanly y Basilia Valenzuela (comps.), Clubes de migrantes oriundos mexicanos en los Estados Unidos: la politica trasnacional de la nueva sociedad migrantes.

\section{ENTREVISTAS Y OTRAS FUENTES}

Gómez, Guadalupe (2002), Presidente de la Federación de Clubes de Zacatecanos del Sur de California, Los Angeles, marzo 10.

GonZÁlez, Javier (2002 y 2003), Presidente del Frente Cívico Zacatecano, Los Angeles, marzo 10 y Zacatecas, enero 9.

GonzÁlez, Javier y Javier Cruz Palomino (2005), Entrevista, Buena Park, California, junio 5 .

GonzÁlez, José (2003), Frente Cívico Zacatecano, Zacatecas, enero 9.

Hernández, José (2002), Miembro de la Federación de Clubes de Zacatecanos de Orange, Cal., Los Angeles, marzo 10.

Resolutivo (2001), Segunda Convención Anual de Organizaciones de Zacatecanos en los Estados Unidos, Chicago, Illinois, julio 21.

Ruiz, Rosalva (2001), Ex-presidenta de la Federación de Clubes Unidos de Zacatecanos en Chicago, Ill., julio.

http://www.comunidadesunidassalvadorenas.org).

http://www.fedreracionzacatecana.org).

http://www.red.indigenanet/organinteg/1fiob.html. 